\title{
Laparoscopic repair of large suprapubic hernias
}

\author{
Hasan Ediz Sikar, Kenan Çetin, Kemal Eyvaz, Levent Kaptanoglu, Hasan Fehmi Küçük \\ Department of General Surgery, Dr. Lutfi Kirdar Kartal Training and Research Hospital, Istanbul, Turkey \\ Videosurgery Miniinv 2017; 12 (3): 245-250 \\ DOI: https://doi.org/10.5114/wiitm.2017.68794
}

\begin{abstract}
Introduction: Suprapubic hernia is the term to describe ventral hernias located less than $4 \mathrm{~cm}$ above the pubic arch in the midline. Hernias with an upper margin above the arcuate line encounter technical difficulties, and the differences in repair methods forced us to define them as large suprapubic hernias.

Aim: To present our experience with laparoscopic repair of large suprapubic hernias that allows adequate mesh overlap.

Material and methods: Nineteen patients with suprapubic incisional hernias who underwent laparoscopic repair between May 2013 and January 2015 were included in the study. Patients with laparoscopic extraperitoneal repair who had a suprapubic hernia with an upper margin below the arcuate line were excluded.

Results: Two men and 17 women, with a mean age of 58.2, underwent laparoscopic repair. Most of the incisions were midline vertical (13/68.4\%). Twelve (63.1\%) of the patients had previous incisional hernia repair (PIHR group); the mean number of previous incisional hernia repair was 1.4. Mean defect size of the PIHR group was higher than in patients without previous repair $-107.3 \mathrm{~cm}^{2}$ vs. $50.9 \mathrm{~cm}^{2}(p<0.05)$. Mean operating time of the PIHR group was higher than in patients without repair - $126 \mathrm{~min} v \mathrm{~s} .77 .9 \mathrm{~min}(p<0.05)$. Although all complications occurred in the PIHR group, there was no statistically significant difference.

Conclusions: Laparoscopic repair of large suprapubic hernias can be considered as the first option in treatment. The low recurrence rates reported in the literature and the lack of recurrence, as observed in our study, support this view.
\end{abstract}

Key words: laparoscopy, incisional hernia, surgical mesh.

\section{Introduction}

Incisional hernias remain one of the major complications in the post-operative period, with a high occurrence rate $(2-11 \%)$ [1]. These types of hernias also carry a high recurrence possibility (63\%) [2]. Laparoscopic repair is one of the treatment options for incisional hernias with decreased recurrence rates and morbidity [3-8]. Suprapubic hernia is the term to describe ventral hernias located less than $4 \mathrm{~cm}$ above the pubic arch in the midline $[9,10]$. The terms "suprapubic" and "parapubic" are often used for the same purpose. Suprapubic hernias are mostly incisional hernias and may be the result of inade- quate fusion when the incision is made in the proximity of the musculotendinous pubic attachment. Most of these hernias occur following low midline or Pfannenstiel incisions applied in gynecological or bowel surgery and in radical prostatectomy [9-14]. Also, suprapubic catheterizations tend to cause this type of hernias [15].

The rare appearance of suprapubic hernia remains a major obstacle for successful treatment of this type of hernia due to limited experience in performing repair using either the open or laparoscopic approach. Inadequate mesh overlap due to proximity to neurovascular structures causes high re-

\section{Address for correspondence}

Hasan Ediz Sikar MD, Department of General Surgery, Dr. Lutfi Kirdar Kartal Training and Research Hospital, Semsi Denizer Street, Cevizli, Kartal, 34845 Istanbul, Turkey, phone: +90 2164583000, e-mail: hasan.sikar@me.com 
currence rates following suprapubic hernia surgery. Laparoscopic repair allows good exposure to identify the hernia defect and neurovascular and bony structures to achieve an adequate mesh overlap of $5 \mathrm{~cm}$. Extraperitoneal repair is not possible for hernias with a superior margin over the arcuate line. Technical difficulty and difference in repair methods forced us to define them as large suprapubic hernias.

\section{Aim}

We aimed to share our experience with laparoscopic repair of large suprapubic hernias (LRSPH) that allows adequate mesh overlap and fixation for the inferior margin.

\section{Material and methods}

Regarding the literature, incisional hernias less than $4 \mathrm{~cm}$ above the pubic symphysis were accepted as suprapubic incisional hernias. Nineteen patients who underwent LRSPH between May 2013 and January 2015 were included in our study. Patients with laparoscopic extraperitoneal repair who had a suprapubic hernia with an upper margin below the arcuate line were excluded from the study. All the operations were performed by a single surgeon in our clinic. Data were collected prospectively including patient characteristics and demographics, number of previous abdominal operations, number of previous hernia repairs, defect size, mesh size, operative time, conversion rate, complications, recurrences and follow-up time.

\section{Operative technique}

The patients were positioned supine, with the left arm tucked. A 3-way Foley catheter and orogastric tube was inserted following anesthesia induction. Instillation of saline via a Foley catheter served to identify the bladder, when necessary. Ports were placed as far away as possible from the hernia in the left lateral side of the abdominal wall for a good view and to allow space for adequate mesh overlap. The first port was inserted close to Palmer's point using an open approach. Pneumoperitoneum was created following insertion of the first port. Two additional ports were placed, to form a triangle, around the first port. All the operations were performed with 3 ports and a 30-degree laparoscope. Contents of the hernia were reduced following exploration of the abdomen; a combination of sharp and blunt dissection with gentle traction was performed (Photo $1 \mathrm{~A}$ ). The distance between the pubic symphysis and the lower margin of the hernia was measured. Also, whether the superior margin of the hernia was above the arcuate line for the decision to perform partially extraperitoneal repair was confirmed. A peritoneal incision, crossing from the inferior margin of the defect - between the anterior superior iliac spines - was made to create a peritoneal flap (Photo $1 \mathrm{~B}$ ). The bladder was mobilized with meticulous dissection to reach the inferior part of the pubic arch (Photo $1 \mathrm{C})$. The pubic symphysis, Cooper's ligaments and iliac vessels were exposed at the end of dissection. The size of the hernia defect was then measured intracorporeally. Parietene Composite (PPC) Mesh (Covidien, Mansfield MA, USA) was used in all patients. The closest available size was used for adequate - about $5 \mathrm{~cm}$ all around the defect - mesh overlap. The mesh was positioned below the pubic symphysis and fixed to the pubic bone and Cooper's ligament with tacks (Photo $1 \mathrm{D}$ ). Superior and lateral edges of the mesh were fixed with pre-tied $2 / 0$ polypropylene suture to position the mesh. Subsequently, titanium helical tacks were used to fix the mesh with the double-crown technique and the peritoneal flap was fixed over the mesh with tacks (Photos 1 E, F).

\section{Statistical analysis}

An Excel worksheet (Microsoft Corp., Redmond, WA) was used to enter data and statistical analysis was carried out using the Statistical Package for Social Sciences software (SPSS Inc. ver. 13.0, Chicago, IL, USA).

\section{Results}

A total of 19 patients, 2 men and 17 women, with a mean age of 58.2, underwent laparoscopic repair (Table I). Most of the patients were obese and the mean body mass index was $35.1 \mathrm{~kg} / \mathrm{m}^{2}$. Only 3 patients had undergone a single previous surgery; the mean number of previous operations was 2.7 and the frequency of gynecological operations was higher than that of bowel-related operations (Table II). Most of the incisions were midline vertical (13/68.4\%) and 2 patients had more than 2 incisions due to previous operations. Eleven (57.8\%) patients had undergone emergency surgery before. Twelve (63.1\%) of 

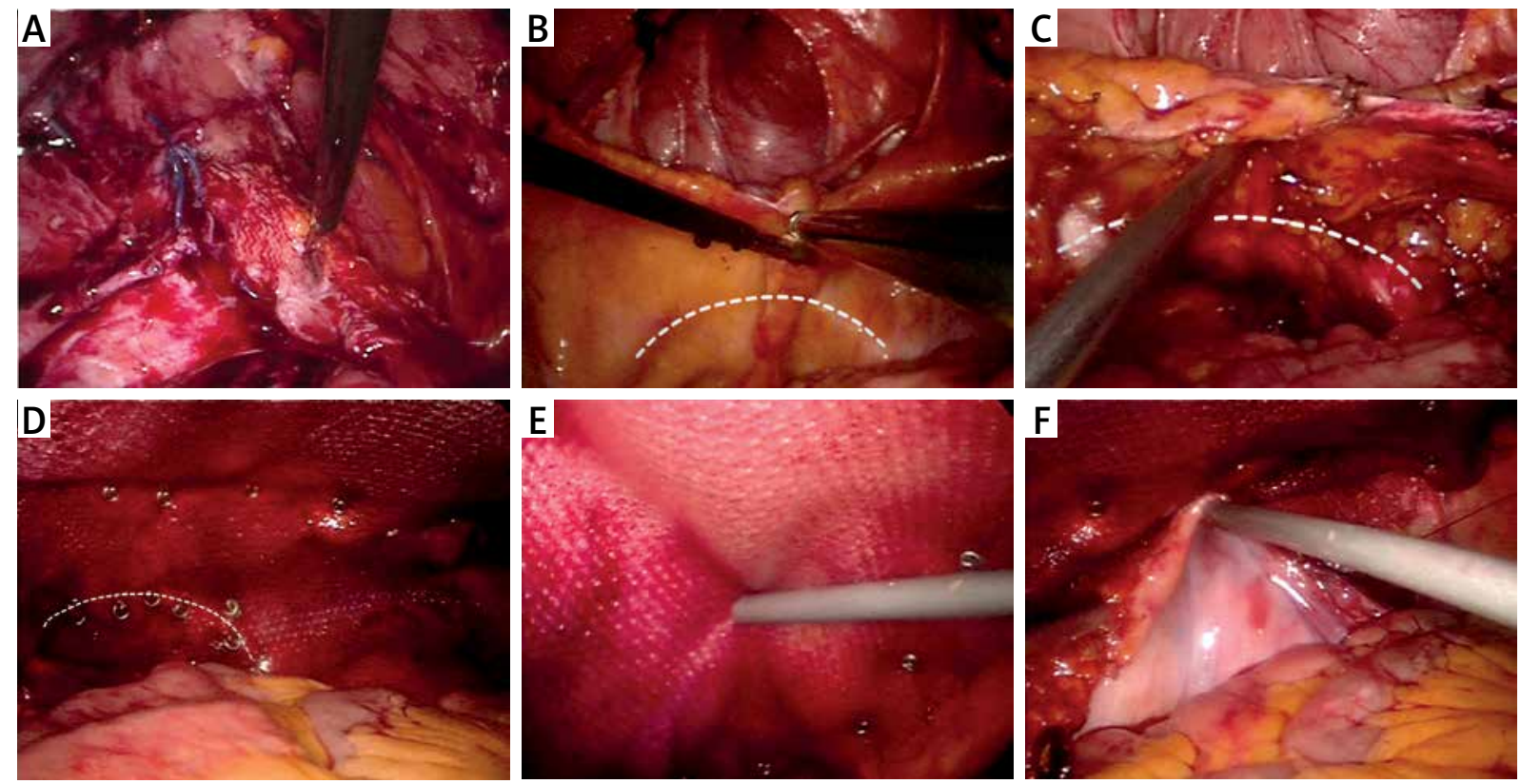

Photo 1. A - Reducing the contents of the hernia, B - Creating the peritoneal flap, crossed from the inferior border of the hernia (pubic arch is marked with dashed line), $\mathbf{C}$ - Meticulous dissection of the bladder to reach inferior part of pubic arch, $\mathbf{D}$ - Fixation of the mesh to the pubic symphysis and Cooper's ligament, $\mathrm{E}$ - Double-crown technique, $\mathrm{F}$ - Closure of the peritoneal flap

the patients had previous incisional hernia repair (PIHR group); the mean number of previous incisional hernia repairs was 1.4 - within a range of 1 to 8 .

The largest hernia defect size was measured as $15 \times 12 \mathrm{~cm}$ and the mean defect size was $86.5 \mathrm{~cm}^{2}$. The mean defect size of the PIHR group was higher than that of patients without previous repair $107.3 \mathrm{~cm}^{2}$ vs. $50.9 \mathrm{~cm}^{2}(p<0.05)$. Mean size of the mesh was $489.5 \mathrm{~cm}^{2}$ and the largest mesh was $20 \times$ $30 \mathrm{~cm}$; none of the patients required more than one mesh. The operating time ranged from 55 to $180 \mathrm{~min}$ and mean operating time was $108.3 \mathrm{~min}$. The mean operating time of the PIHR group was higher than that of patients without repair -126 min vs. $77.9 \mathrm{~min}$ $(p<0.05)$.

There was no conversion in our study. Complications occurred in $21.1 \%$ of the patients, as depicted in Table I. One patient had prolonged ileus. The patient could be discharged on postoperative day 4 and did not require additional intervention. Two patients had symptomatic seroma; one of them required single aspiration, whereas the other patient needed aspiration 3 times. One patient had pain for more than 6 weeks after surgery. Oral analgesics were sufficient for this patient and they were not needed after 12 weeks. Although all complications
Table I. Characteristics of patients

\begin{tabular}{|lc|}
\hline Parameter & Value \\
\hline Gender (male/female) & $2 / 17$ \\
\hline Age & $58.2 \pm 6.6$ \\
\hline BMI $\left[\mathrm{kg} / \mathrm{m}^{2}\right]$ & $35.1 \pm 7.2$ \\
\hline Defect size $\left[\mathrm{cm}^{2}\right]$ & $86.5 \pm 45.9$ \\
\hline Mesh size $\left[\mathrm{cm}^{2}\right]$ & $489.5 \pm 137.1$ \\
\hline Operation time [min] & $108.3 \pm 42.1$ \\
\hline Length of stay [day] & $1.5 \pm 0.9$ \\
\hline Follow-up time [month] & $31.2 \pm 5.9$ \\
\hline \begin{tabular}{l} 
Complications: \\
\hline Prolonged ileus
\end{tabular} & 1 \\
\hline \begin{tabular}{l} 
Symptomatic seroma \\
\hline Chronic pain
\end{tabular} & 1 \\
\hline
\end{tabular}

occurred in the PIHR group, no statistically significant difference was observed.

Mean length of stay was 1.5 days, in the range of 1-4 days. Mean follow-up time was 31.2 months and no recurrence was observed during the follow-up period. 
Table II. Properties of previous operations in patients

\begin{tabular}{|lccc|}
\hline Variable & Gynecological & Bowel & Number of operations \\
\hline Type of previous operation & 10 & 9 & $2.7 \pm 2.1$ \\
\hline Previous incisional hernia repair & 6 & 6 & $1.4 \pm 2.2$ \\
\hline Midline incision & 6 & 2 & \\
\hline Pfannenstiel + midline incision & 2 & - & \\
\hline Multiple incisions & 2 & & \\
\hline
\end{tabular}

\section{Discussion}

Contents of the anterior abdominal wall end up with a musculotendinous insertion into the pubic symphysis. The insertion into the pubis comprises relatively weak tissue and incisions placed close to this insertion may result in inadequate fusion. Also, inadequate tissue approximation of the inferior side during primary closure may increase the risk of hernia formation. Pfannenstiel incision and lower midline vertical incisions are the most common causes of suprapubic hernias [9-14]. We faced midline vertical incisions rather than Pfannenstiel incisions in our series. The exact incidence of suprapubic hernia is not known; Palanivelu et al. reported an incidence of $3.4 \%$ throughout their 8 years of experience [10]. We saw a higher incidence of $14.4 \%$ (19/132 cases) in 21 months. Almost all the patients were referred from state hospitals; ours being a tertiary referral hospital might be the possible reason for higher incidence. This reality has also affected our indications for incisional hernia repair. For some of the surgeons,

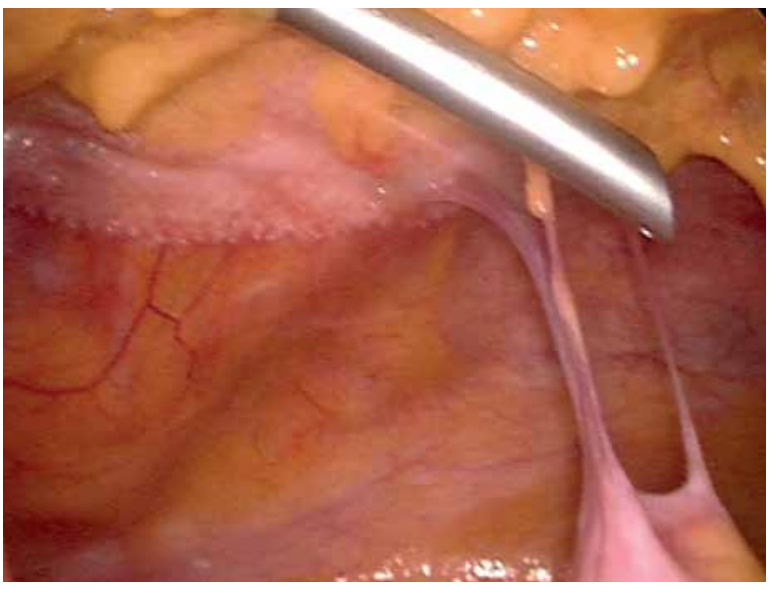

Photo 2. Adhesions to the composite mesh in a patient with previous laparoscopic Spiegelian hernia repair obesity, age, defect size, smoking or asymptomatic hernia could be the reasons not to operate [16]. All the patients who underwent incisional hernia repair were symptomatic in our series and most of them had made a visit to the emergency unit in a state hospital more than once before. Therefore, only a high operation risk due to anesthesia was our contraindication for incisional hernia repair.

The urinary bladder, vascular and neural structures are near the defect; consequently an inadequate number of permanent structures to fix the mesh prevents a proper hernia repair. Therefore, suprapubic hernias have been considered difficult to repair in the past. There are few reports specifically related to laparoscopic repair of suprapubic hernias. Incising the peritoneum to create a flap, entering the space of Retzius and exposing vital structures are common steps in the procedure [9-13]. These steps are similar to those in the transabdominal preperitoneal (TAPP) procedure $[17,18]$. The experience gained through laparoscopic inguinal hernia repair raises our prospects for proper identification at this stage. The double-crown technique is our choice of treatment in incisional hernias; if necessary, we use transabdominal sutures to position a large mesh properly. Carbonell et al. reported two cases of recurrence before applying multiple sutures directly to the pubis and Cooper's ligament [11]. Contrary to recommendations in the literature, we did not apply transabdominal sutures to fix the inferior border of the mesh and recurrence was not observed during the follow-up period. Absence of recurrence can be supportive of the idea that the inferior border of the mesh receives adequate support, even though it is not fixed with transabdominal sutures. However, further comparative studies are required to verify this opinion. Complication rates of $16.6 \%$ to $38 \%$ have been reported in previous studies; our complication rate was $21.1 \%$. None of the complications 
occurred during the operation. As we have already mentioned, experience gained during laparoscopic inguinal hernia repair allows proper identification of this region.

Laparoscopic extraperitoneal repair is possible with full coverage of the peritoneal flap, as in the TAPP procedure, in most of the suprapubic hernias below the arcuate line. The technical difficulty in repairing a hernia that extends along the abdominal wall is not observed in this type of suprapubic hernia. Also, there is no need to use a composite mesh when an extraperitoneal repair is possible. Therefore, in this study, the definition "large" was used for hernias which passed over the arcuate line. In previous studies, the peritoneal flap was left in place or fixed to reperitonealize as much of the mesh as possible [9-12]. Although there is no complication associated with leaving the peritoneal flap in place, we have fixed the flap over the mesh. Peritoneal adhesions, acute mechanical intestinal obstruction (AMIO) and fistula formation are possible complications of intra-peritoneal mesh placement. Although no AMIO or fistula formation was observed, adhesions to the mesh in some of our patients who underwent laparoscopic ventral hernia repair were observed, during other laparoscopic operations (Photo 2). Owing to lessons learned from adhesions that could also occur to composite mesh, to reduce the possibility of adhesions, covering the mesh with a peritoneal flap is necessary if possible. Also, a study considering the specialists' choice of treatment was noteworthy. Pawlak et al. reported that mesh peritonealisation was the most popular method when considering a laparoscopic approach below the pubic bone and Cooper's ligament [19].

Patients with previous incisional hernia repair in our series had undergone open surgery before and had a greater defect size and longer operation time $(p<0.05)$. Inadequate mesh overlap during open surgery might be the cause of higher defect size in subsequent operations. Also, adhesions to the mesh and adhesiolysis due to previous repair have prolonged the operation time. Although no statistically significant difference was observed, patients without previous incisional hernia repair had no complications.

\section{Conclusions}

Laparoscopic repair of large suprapubic hernias can be considered as the first option in treatment.
The low recurrence rates reported in the literature and the lack of recurrence, as observed in our study, support this view.

\section{Conflict of interest}

The authors declare no conflict of interest.

\section{References}

1. Shell DH $4^{\text {th }}$, de la Torre J, Andrades P, et al. Open repair of ventral incisional hernias. Surg Clin North Am 2008; 88: 61-83.

2. Burger JW, Luijendijk RW, Hop WC, et al. Long-term follow-up of a randomized controlled trial of suture versus mesh repair of incisional hernia. Ann Surg 2004; 240: 578-83.

3. Nardi M Jr, Millo P, Brachet Contul R, et al. Laparoscopic ventral hernia repair with composite mesh: analysis of risk factors for recurrence in 185 patients with 5 years follow-up. Int I Surg 107; 40: 38-44.

4. Grubnik VV, Grubnik AV, Vorotyntseva KO. Laparoscopic repair of incisional and ventral hernias with the new type of meshes: randomized control trial. Videosurgery Miniinv 2014; 9: 145-51.

5. Itani KM, Hur K, Kim LT, et al. Comparison of laparoscopic and open repair with mesh for the treatment of ventral incisional hernia: a randomized trial. Arch Surg 2010; 145: 322-8.

6. Barbaros U, Asoglu O, Seven R, et al. The comparison of laparoscopic and open ventral hernia repairs: a prospective randomized study. Hernia 2007; 11: 51-6.

7. Misra MC, Bansal VK, Kulkarni MP, et al. Comparison of laparoscopic and open repair of incisional and primary ventral hernia: results of a prospective randomized study. Surg Endosc 2006; 20: $1839-45$

8. Saglam F, Keskin G, Özmen V, et al. Laparoscopic intraperitoneal prosthetic mesh placement in ventral-incisional hernias. Ulus Cerrahi Derg 2004; 20: 164-72.

9. Sharma A, Dey A, Khullar R, et al. Laparoscopic repair of suprapubic hernias: transabdominal partial extraperitoneal (TAPE) technique. Surg Endosc 2011; 25: 2147-52.

10. Palanivelu C, Rangarajan M, Parthasarathi R, et al. Laparoscopic repair of suprapubic incisional hernias: suturing and intraperitoneal composite mesh onlay. A retrospective study. Hernia 2008; 12: 251-6.

11. Carbonell AM, Kercher KW, Matthews BD, et al. The laparoscopic repair of suprapubic ventral hernias. Surg Endosc 2005; 19: 174-7.

12. Varnell B, Bachman S, Quick J, et al. Morbidity associated with laparoscopic repair of suprapubic hernias. Am J Surg 2008; 196 : 983-7.

13. Hope WW, Hooks WB $3^{\text {rd }}$. Atypical hernias: suprapubic, subxiphoid and flank. Surg Clin North Am 2013; 93: 1135-62.

14. Kisielinski K, Conze J, Murken AH, et al. The pfannenstiel or so called "bikini cut": still effective more than 100 years after first description. Hernia 2004; 8: 177-81.

15. Lobel RW, Sand PK. Incisional hernia after suprapubic catheterization. Obstet Gynecol 1997; 89: 844-6.

16. Nieuwenhuizen J, Kleinrensink GJ, Hop WC, et al. Indications for incisional hernia repair: an international questionnaire among hernia surgeons. Hernia 2008; 12: 223-5. 
17. Yang XF, Liu JL. Laparoscopic repair of inguinal hernia in adults. Ann Transl Med 2016; 4: 402.

18. Carter J, Duh QY. Laparoscopic repair of inguinal hernias. World J Surg 2011; 35: 1519-25.

19. Pawlak M, Bury K, Smietanski M. The management of abdominal wall hernias - in search of consensus. Videosurgery Miniinv 2015; 10: 49-56.

Received: 27.03.2017, accepted: 23.05.2017. 